\title{
Is MRI imaging in pediatric age totally safe? A critical reprisal
}

\author{
Sergio Salerno ${ }^{1}$ (D) Claudio Granata ${ }^{2} \cdot$ Marco Trapenese $^{3} \cdot$ Vittorio Cannata $^{4} \cdot$ Davide Curione $^{5}$. \\ Maria Camilla Rossi Espagnet ${ }^{5} \cdot$ Andrea Magistrelli $^{5} \cdot$ Paolo Tomà $^{5}$
}

Received: 20 October 2017 / Accepted: 20 April 2018 / Published online: 3 May 2018

(C) Italian Society of Medical Radiology 2018

\begin{abstract}
Current radiological literature is strongly focussed on radiation imaging risks. Indeed, given there is a small but actual augment in cancer risk from exposure to ionizing radiation in children, it is important to understand what the risk of alternative techniques could be. We retrospectively review literature data concerning possible MR imaging risks, focussing on the biological effects of MR, sedation and gadolinium compound risks when dealing with infant patients. The main concerns can be summarized in: (1) Biological effects of non-ionizing electromagnetic fields (EMF) employed—whose mechanisms of interaction with human tissues are polarization, induced current, and thermal heating, respectively. (2) Risks associated with noises produced during MRI examinations. (3) Hazards from ferromagnetic external and/or implanted devices-whose risk of being unintentionally brought inside MR room is higher in children than in adults. (4) Risks associated with sedation or general anaesthesia, essential problem in performing MR in very young patients, due to the exam long-lasting. (5) Risks related to gadolinium-based contrast agents, especially considering the newly reported brain deposition.
\end{abstract}

Keywords MR $\cdot$ Safety $\cdot$ Paediatric population

\section{Introduction}

Current radiological literature is strongly focussed on radiation imaging risks [1]; it may be worthwhile to assess the safety of alternative imaging modalities used in the paediatric population. Since it is a small but actual augment in cancer risk from exposure to ionizing radiation in children, it is important to understand what the risks of alternative techniques could be.

Sergio Salerno

sergio.salerno@unipa.it

1 Dipartimento di Diagnostica per Immagini, Policlinico Università degli Studi di Palermo, Via del Vespro 127, CAP 90127 Palermo, Italy

2 UOC Radiologia - Ospedale Pediatrico Giannina Gaslini, Genoa, Italy

3 Dipartimento di Energia, Ingegneria dell'Informazione e Modelli Matematici, Università degli Studi di Palermo, Palermo, Italy

4 Servizio Prevenzione e Protezione/Fisica Sanitaria, Ospedale Pediatrico Bambino Gesù, Rome, Italy

5 Dipartimento Diagnostica per Immagini, Ospedale Pediatrico Bambino Gesù, Rome, Italy
Therefore, the aim of this article was to make a risk/benefit analysis of avoiding the use of X-rays in favour of other imaging modalities, focusing our attention on MR imaging (MRI). To achieve this goal, we investigated the recent literature and reviewed our experience to optimize the MR approach in children.

\section{Methods}

We performed a PubMed research ("Magnetic Resonance Imaging"[Mesh] AND "safety"[Mesh]), obtaining 817 results. Adding the filter "Child: birth -18 years", the papers were reduced to 125 . Search results for (("gadolinium"[MeSH Terms] OR "gadolinium"[All Fields]) AND deposition [All Fields] AND ("brain"[MeSH Terms] OR "brain”[All Fields])) were 142 papers.

Lastly, searching for ("Magnetic Resonance Imaging"[Mesh] AND "safety"[Mesh] AND "sedation") we obtained 22 papers. If integrated with ("safety" [MeSH Terms] OR "safety"[All Fields]) AND ("pediatrics"[MeSH Terms] OR "pediatrics"[All Fields] OR "pediatric"[All Fields]) AND "MRI”[All Fields], found papers were 564. 
Among those papers, we focussed on articles specifically addressed to risks of MRI safety on paediatric population, about biological effects, gadolinium-related and sedation risks at the end we selected 73 articles and statements considered more relevant according to author's agreement that are discussed in this paper.

\section{Risks related to MRI medical examinations in the paediatric population}

MRI related risks can be summarized in: biological effects of non-ionizing electromagnetic fields (EMF) employed; risks from noises produced during MRI examinations; hazards from ferromagnetic external and/or implanted devices; risks associated with sedation or general anaesthesia or related to gadolinium-based contrast agents (GBCA) [2].

\section{Biological effects of non-ionizing electromagnetic fields employed in MRI}

The three sources of EMF used in MRI are the following: static magnetic fields (SMF), gradient fields (GMF), and radiofrequency (RF). The mechanisms of interaction with human tissues are polarization, induced current, and thermal heating, respectively. FDA has approved exposure of adults to $7 \mathrm{~T}$ fields and exposure of neonates to $4 \mathrm{~T}$ fields.

Usually, Institutional Review Boards (IRBs) define MRI as a minimal risk technique so it is approved for numerous research protocols, including in children [3]. Minimal risk means "the probability (of occurrence) and magnitude (seriousness) of harm or discomfort (e.g. psychological, social, legal, economic) associated with the research are not greater than those ordinarily encountered in daily life (of the average person in the general population) or during the performance of routine physical or psychological examinations or tests." [4].

MRI is considered the safe alternative to CT, but paradoxically, one of the most alarming issues concerning MRI regards the possible "genotoxic" effects [5].

Hartwig [6] demonstrated that EMF generated during MRI diagnostic scans have genotoxic effects, in terms of micronuclei (MN) induction (carcinogenesis). Anyway, the genetic damage should be reversible: after $48 \mathrm{~h}$, the $\mathrm{MN}$ number returned to that of the controls, suggesting that two cell divisions are enough to eliminate them. In conclusion, the authors suggested prudent use to avoid superfluous examinations, according to the precautionary principle. However, the precautionary principle is positive only if the restraint of a procedure has less damaging side effects than benefits of usage [7]. Simi [8] reported a dose-dependent (1.5 T scanner, with a maximum gradients strength of $50 \mathrm{mT} \mathrm{m}^{-1}$, and a maximum gradients speed of $150 \mathrm{mT} \mathrm{m}^{-1} \mathrm{~s}^{-1}$ ) increase of $\mathrm{MN}$ frequency in vitro that returned to control values after $24 \mathrm{~h}$ when the exposure was within diagnostic levels. In vivo, a significant increase in $\mathrm{MN}$ was found till $24 \mathrm{~h}$ and after the frequencies slowly returned to control values. [9].

The issue of biological damage and DNA repair capacity is also the key point of the studies on detrimental effect of $\mathrm{X}$-ray radiation [10]. Kuefner [11] stressed that individual factors, including radiation sensitivity and DNA repair capacity, determine the DNA damage level. There may be similar assumptions for MR, but according to Leszczynski, even if single EMF exposures cause only negligible fully reversible effects, i.e. slightly changed phosphorylation of proteins, multiple EMF tests might increase the risk that one of these changes might lead to an irreversible effect [12]. The dilemma is: in children's growing organs mitoses are more frequent, but cancer incidence significantly increases in the elderly [13]. The apparent contradiction is likely to be justified in the greater potential of chromosome damage repair in children. Besides, in everyday life, we are subjected to a series of environmental insults that cannot be genotoxic "in themselves", but may increase the negative effects of other biological, chemical and/or physical agents [8]. In a study by Magin [14] on (sub) chronicle exposures, no statistically significant changes were observed in foetal growth in animals (mice) exposed to only MR or ultrasound fields. Conversely, in the combined ultrasound and MR exposed group, foetal weight and crown-rump length were reduced compared to the controls. Luckily, analysis of cognitive and biometric data from a decade-long longitudinal fMR study of normal language development in a small, longitudinal sample of healthy children who received up to $10 \mathrm{MR}$ scans provided evidence of minimal (if any) risk [3]. Salerno et al. demonstrated the effect on human lymphocyte activation cytokine release by SMF in 0.5 T MR $[15,16]$.

The most common/known biological problem during MR is that of heating, due to RF fields [17]. This heating of tissues is maximum at the surface and minimal at the centre of the body. A rise of $1{ }^{\circ} \mathrm{C}$ is generally acceptable for a normal healthy body. Usually, there are no problems in adults, who dissipate heat mainly with peripheral vasodilatation. Infants and newborns, particularly if preterm, have immature thermoregulation $[17,18]$. The RF power absorbed per unit of mass of an object is defined Specific Absorption Rate (SAR) and is measured in watts per kilogram $\left(\mathrm{W} \mathrm{kg}^{-1}\right)$. SAR rises with the square of the static MF. To avoid overheating of any local area, the limits of the product of time and local SAR (W min $\mathrm{kg}^{-1}$ ) are defined by international guidelines. For exposures of infants, a reduction of these values by a factor of two is recommended $[18,19]$. For children in general and infants/newborns, the time factor is crucial. Many technical issues cause an increase of examination time, such as smaller coils to maximize local signal (enclosing a larger portion of the body, and augmenting RF heating in turn), 
respiratory triggering and cardiac gating, and controlled ventilation [20].

During sedation/anaesthesia, which limits intrinsic thermoregulation, body temperature is the result of a sum of factors: the cool environment, hypothermia because of passive heat loss (large surface area-to-body weight ratio), heating due to RF fields [21]. According to Isaacson, hypothermia $\left(-1{ }^{\circ} \mathrm{C}\right.$ or more) is possible in young patients propofolsedated [22]. Conversely, a case of iatrogenic hyperthermia occurring in a 16-month-old infant during anaesthesia for cardiac MR (fentanyl, rocuronium, sevoflurane) was reported [23]. The patient was scanned with a head coil for 19 consecutive series over $95 \mathrm{~min}$ with a $1.5 \mathrm{~T}$ magnet. The pulse sequences included fast spin echo sequences, which are associated with the highest SARs. At the end of the examination, the heart rate was $200 \mathrm{bpm}$ and axillary temperature was $38{ }^{\circ} \mathrm{C}$. Other series of infants propofolsedated do not confirm hypothermia, reporting a prevalence of heating: probably, the depth of sedation may influence the degree of thermoregulatory impairment [24]. In summary, local temperature fluctuations are difficult to predict.

\section{Risks related to noises produced during MR examinations}

Various types of acoustic noise are produced during MRI. The primary source of noise is the GMF with flexing and vibration of the gradient coils [25]. The noise is manifested as loud tapping, knocking, or chirping sounds. Neonates with undeveloped anatomical structures may have an amplified reaction to acoustic noise, i.e. important changes in vital signs of newborns have been described during MR examinations, which may be due to acoustic noise. This could augment the chance of hearing loss and could have an adverse effect on neurosensory and physiologic short-term and long-term natural growth and development of the neonate [26]. Noise levels differ with diverse MR sequences and are directly related to static field strength [25]. MHRA states [27]: the use of earplugs, ear defenders, or other hearing protections is highly recommended. Groups of concerns are paediatric and neonate patients, and the foetus. It is recommended that staff and others remaining in the scan room (i.e. parents) wear non-metallic earplugs and/or ear defenders. In the case of the anaesthetized patients, hearing protection should always be provided. Another source of acoustic noise is the so-called RF hearing (click, buzz, chirp, or knocking noise) [25].

Time-varying magnetic fields also induce electric fields in patients, stimulating nerves or muscles. At sufficient amplitudes, peripheral nerve stimulation is perceptible (i.e. tingling or tapping sensations). Safety standards avoid cardiac stimulation [28].

\section{Risks from ferromagnetic external objects and implanted devices}

The risk of ferromagnetic projectiles unintentionally carried inside the scanning room of an MR setting is greater in children (especially in the newborns and infants) than in adults. If a young child needs MR, the clinical problem is usually severe and almost always sedation or anaesthesia is necessary. Usually, they have supplementary equipment, such as monitoring, ventilation and infusion pumps. As synthesized by Arthur [17]: proper requirements must be accessible when sick young children are in the MR environment: MR-compatible fibre-optic temperature monitoring, pulse oximeter, ECG leads. Standard equipments such as laryngoscope blades, handles and stethoscopes are usually not MR compatible. All emergency care is best performed outside the immediate scanner environment (outside the 5-Gauss line) to minimize the risk of ferromagnetic projectile.

Concerning implanted devices, these are special in children and must be known (Fig. 1). They can determine electromagnetic field interactions, MR-related heating, and the creation of artefacts. As well as longer-term central venous catheters, implanted programmable cerebrospinal fluid (CSF) shunts (to be resected after imaging), implanted cardiac devices and cochlear implants are typical of paediatric patients. The FDA's Centre for Devices and Radiological Health (CDRH) proposes terms to be used to label MR information for medical devices [29]:

- MR Safe: an item that poses no known hazards in all MR environments;

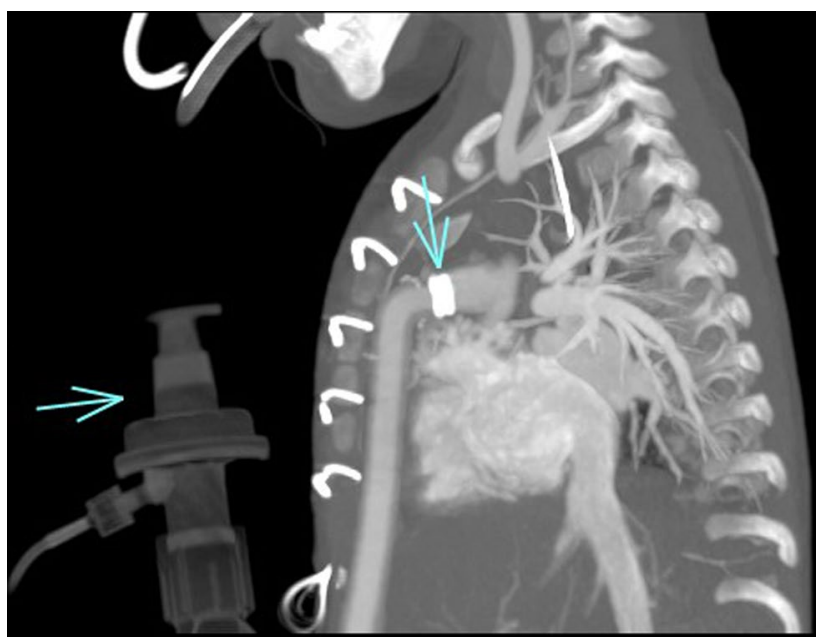

Fig. 1 CT angiography sagittal reconstruction of a 1-year-old female with congenital heart disease with Berlin Heart, a paediatric mechanical ventricular assist device (arrow); in these cases, magnetic resonance (MR) imaging is contraindicated 
- MR Conditional: an item that has been demonstrated to pose no known hazards in a specified MR environment with specified conditions of use;

- MR Unsafe: an item that is known to pose hazards in all MR environments.

Owing to the complexity of the conditions faced and the heterogeneity of the implanted devices, in our Hospital we identified a flow chart that has the justification of the examination as starting point and subsequently advises that the physician retrieves the information on the device from the manufacturer, identifying the degree of MR safety. The increasing amount of data on all specific devices will ultimately allow to build a database, enabling real-time decisions.

\section{Risks associated with sedation and anaesthesia}

The most common cause of artefacts on MR images is patient motion. In children, the mix of patient collaboration, fast/irregular respiratory frequency, and tiny anatomy can make the exam extremely challenging. In MR performed in paediatric patients, spatial resolution is crucial, but unfortunately there is an inverse relationship between spatial resolution and signal-to-noise ratio (SNR), which is proportional to the square root of the acquisition time [30].

NICE guidelines suggest [31]: "for children and young people $[\ldots]$ during diagnostic imaging consider either chloral hydrate for children under $15 \mathrm{~kg}$, or midazolam. If these are not suitable, consider one of the following drugs ministered by a specialist healthcare professional with a narrow margin of safety: propofol, sevoflurane". Long scan times evidently make sedation/anaesthetic indispensable in paediatric MR [32]. The principal short-term risks are under-sedation or over-sedation. Under-sedation is inadequate reduction of movements to obtain diagnostic images. In younger children, over-sedation increases the risk of desaturation or apnoea. Furthermore, adverse events, especially pulmonary complications, also include patients with obesity, history of snoring, and developmental disabilities. In children with congenital cardiac diseases, the frequency of adverse events was estimated to be between 0 and $10.4 \%$ [33] and direct patient observation is prevented by physical separation. Besides, little is known about the long-term effects after exposure to analgesics or sedatives [34]. Practices for the induction of general anaesthesia, as masks or cannulas, can also create panic in the child [32]. Alternative techniques such as oral sucrose solution, "feed and wrap" or "feed and sleep" practices can be valid solutions. According to Edwards [32], "feed and wrap" is ideal for children younger than 1 year, oral or intravenous sedation between 1 and 5 years, and distraction therapies for $>6$ year olds. Usually, the necessity of "urgent" examinations favours anaesthesia (i.e. baseline oncology imaging that implies prolonged examination times). There is a need to balance the choice between the risk of failing the exam, the use of alternative techniques such as CT (considering any diagnostic limits), and performing anaesthesia directly (if the organization allows it) [35].

In any case, intensive use of techniques to reduce artefacts, such as respiratory gating (or triggering), respiratory compensation (or phase re-ordering), navigator echoes, ECG gating, contributing to long acquisition times, is required in children.

\section{Risks associated with gadolinium-based contrast agents (GBCA)}

GBCAs can increase the accuracy of MR examinations, but many risks associated with the administration of exogenous contrast media must be taken into account [36]. All GBCAS are administered to humans in the form of chelates to avoid the presence of free gadolinium $(\mathrm{Gd} 3+)$, which is toxic. The molecular structure can be linear or macrocyclic, and ionic or non-ionic. In linear GBCAs, the ion of Gd is surrounded by an open structure. Macrocyclic agents have a complete ring encasing the ion of Gd in a structure which tends to hold it more firmly, thus being more resistant to its release [37]. The association between GBCA exposure and the development of Nephrogenic Systemic Fibrosis (NSF) is widely accepted [38]. In healthy individuals, the half-life of GBCAs is usually $1.5 \mathrm{~h}$, while in severely impaired renal function patients the half-life is increased up to approximately $30 \mathrm{~h}$ [39]. Only 23 paediatric NSF cases have been described and all patients were 6 years of age or older. Seventeen of these children had documented exposure to GBCAs [40].

The association of brain MR abnormalities (Abnormal T1 Shortening in Deep Brain Areas) with a history of linear GBCA administration was firstly reported by Kanda [41]. Increased signal intensity in the dentate nucleus and globus pallidus on unenhanced T1-weighted images (T1WI) showed a positive correlation with previous exposure to GBCAs with an apparent dose-response relationship (Fig. 2a, b). Macrocyclic GBCAs seem to be less linked to this phenomenon [42-47]. The same phenomenon has been also reported in children [48-53]. The studies have been focused in three directions: (1) detection of increased T1-weighted signal intensity (SI) or R1 relaxation rate in deep grey matter structures; (2) direct detection of Gd and measurement of Gd concentration in human tissues (brain, other organs) [45] [54-57]; (3) animal studies (detection and measurement of Gd levels, imaging investigations, Gd deposit speciation) [58-60]. To date, no histological changes in brain tissues 

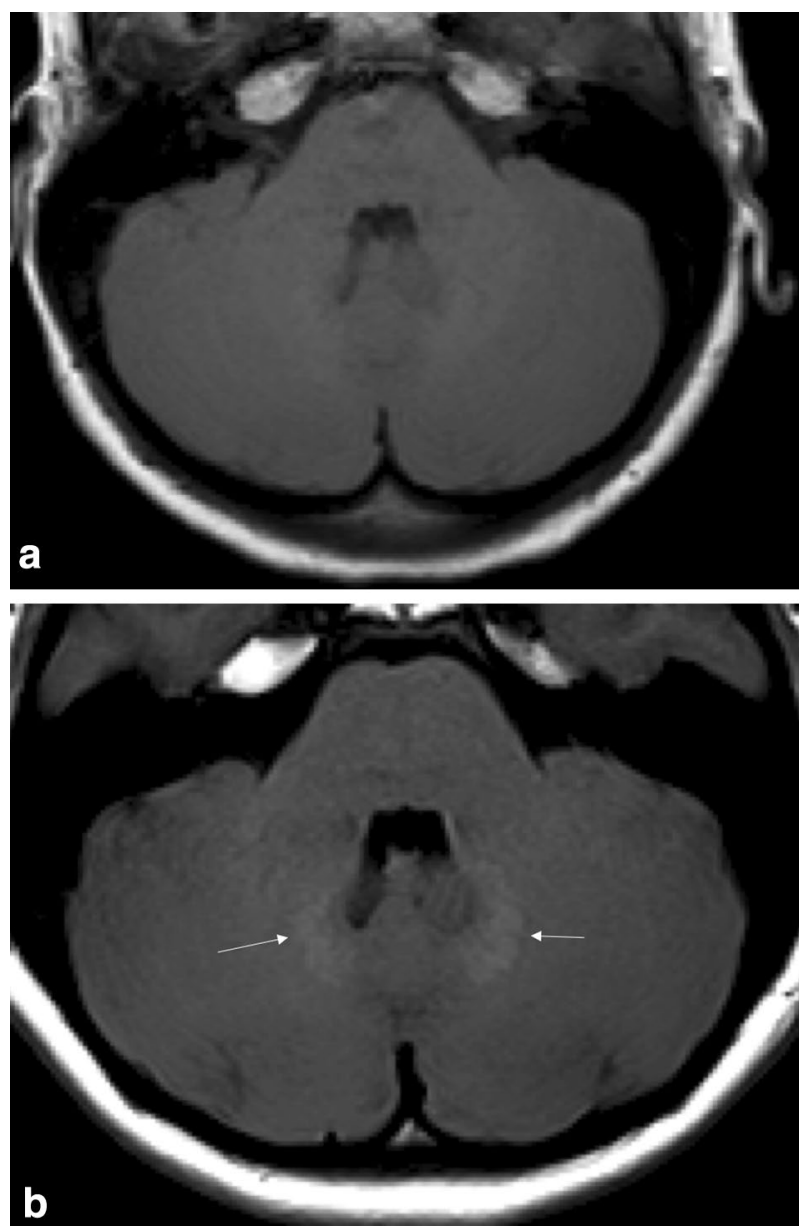

Fig. 2 a, b Pre-contrast T1-weighted images of a 13-year-old girl affected by suprasellar germinoma treated with chemotherapy and radio-therapy. a First MRI at the onset (11 years). A clear dentate nucleus hyperintensity (arrows) is visible after 6th from previous MR (b); only a macrocyclic GBCA was used

after repeated GBCA administration have been found. Clinical significance of gadolinium deposition and potential longterm consequences in the brain remain unclear. For all these reasons, EMA's Committee for Medical Products for Human Use (CHMP) has recently published several precautions and recommendation on the use of GBCAs for MR [61].

ESUR Contrast Medium Safety Committee recommends avoiding unnecessary exposure of children to GBCAs, especially in neonates and infants. Contrast agents with highest risk of NSF (linear) are contraindicated in neonates and should be used with caution in children aged less than 1 year [62]. However, Bedoya [63] investigated the effect of intravenous contrast material (linear) on renal function in a large population of neonates and concluded that, in the absence of known renal failure, neonates receiving standard patient care do not appear to be at increased risk for developing renal toxicity due to the administration of intravenous iodine- or gadolinium-based contrast media.
Paediatric acute allergic-like reactions to GBCA are rare: $0.04-0.08 \%$ per dose vs. $0.18 \%$ for iodinated contrast agents [5, 64-66].

\section{Conclusions}

The main role of imaging is to help patients by influencing clinical management, simultaneously reducing imagingrelated risks without negative consequences on efficacy as much as possible. MR is paramount in the evaluation of the brain, musculoskeletal system, and spine. As for the abdomen, MR is multi-parametric and has an incomparable contrast resolution, excellent for oncology. In detail, it can create a variety of tissues contrasts that can even be coregistered, increasing lesion conspicuity [30, 67].

Unfortunately, MR is also somewhat operator dependent in its execution and, to be effective, time consuming. Conversely, CT is faster, cheaper, and much easier to perform. As Arthurs stated [5]: a well-performed CT will yield better diagnostic information than a poorly performed MR. The duration of MR means sedation or anaesthesia and risks of over-sedation, causing respiratory depression. The major events requiring resuscitation occur in $1 \%$ of patients, depending on the exact drug regimen used and staff experience [35]. Paradoxically, in this context the main risk in imaging concerns MR. The drawback of CT is the risk of ionizing radiation. Syndrome associated with paediatric tumours, such as Beckwith-Wiedemann syndrome and, even more, DNA repair diseases (Fanconi anaemia, ataxiatelangectasia, etc.), which are characterized by immunodeficiency and/or predisposition to cancer development, need a screening by imaging [68-70]. Despite the presumed genotoxicity, MR is considered the technique of choice in this case: many cancer-prone diseases have been shown to be radiosensitive due to pitfalls in the mechanisms of repair of induced DNA lesions.

Up to date there is not yet an adequate consensus about the MR-related cancer risks and the World Health Organization affirmed that "the carcinogenicity of static magnetic fields to humans is not at present classifiable". But a study conducted by Ray et Al must be mentioned, since it demonstrated that there is not actual carcinogenetic risk, when performing MR in foetal period-first trimester [70, 71].

Whole-body MR (WB-MR) is an increasingly used technique in paediatric oncology (Sequences that are typically employed in WB-MR include short tau inversion recovery (STIR), usually obtained using respiratory compensation techniques, and diffusion-weighted whole-body imaging with background body signal suppression (DWIBS), which are free breathing sequences [72]. The limits of WB-MR are poor sensitivity (motion artefacts, partial volume planes) and poor specificity (pitfalls due to growth variants) [73]. 
Besides, technological advancements in CT (reduced radiation doses in sub-second scan times) improve the potentials of $\mathrm{CT}$ and we should re-evaluate its use in at-risk paediatric patients. Diagnostic images are produced without breathholds and patient cooperation and, thus, without general anaesthesia. A typical example is Cardiac CT [33].

In summary, particularly in young children, the choice between CT and MR should be decided on a case-by-case basis, considering efficacy first and avoiding radio-phobic attitudes. Of course, the costs, the urgency, and the availability of machines also play a primary role.

\section{Compliance with ethical standards}

Conflict of interest The authors declare that they have no conflict of interest.

Ethical standards This article does not contain any studies with human participants performed by any of the authors. This article does not contain any studies with animals performed by any of the authors.

\section{References}

1. Toma P, Cannata V, Genovese E, Magistrelli A, Granata C (2017) Radiation exposure in diagnostic imaging: wisdom and prudence, but still a lot to understand. Radiol Med 122(3):215-220. https:// doi.org/10.1007/s11547-016-0709-3

2. Expert Panel on MRS, Kanal E, Barkovich AJ, Bell C, Borgstede JP, Bradley WG Jr, Froelich JW, Gimbel JR, Gosbee JW, KuhniKaminski E, Larson PA, Lester JW Jr, Nyenhuis J, Schaefer DJ, Sebek EA, Weinreb J, Wilkoff BL, Woods TO, Lucey L, Hernandez D (2013) ACR guidance document on MR safe practices: 2013. J Magn Reson Imaging 37(3):501-530. https://doi. org/10.1002/jmri.24011

3. Holland SK, Altaye M, Robertson S, Byars AW, Plante E, Szaflarski JP (2014) Data on the safety of repeated MRI in healthy children. Neuroimage Clin 4:526-530. https://doi.org/10.1016/j. nicl.2014.01.013

4. Braunschweiger P, Goodman KW (2007) The CITI program: an international online resource for education in human subjects protection and the responsible conduct of research. Acad Med 82(9):861-864. https://doi.org/10.1097/ACM.0b013e31812f777 0

5. Arthurs OJ, Bjorkum AA (2013) Safety in pediatric imaging: an update. Acta Radiol 54(9):983-990. https://doi.org/10.1177/02841 85113477399

6. Hartwig V, Giovannetti G, Vanello N, Lombardi M, Landini L, Simi S (2009) Biological effects and safety in magnetic resonance imaging: a review. Int J Environ Res Public Health 6(6):17781798. https://doi.org/10.3390/ijerph6061778

7. Siegel JA, Sacks B, Pennington CW, Welsh JS (2017) Dose optimization to minimize radiation risk for children undergoing $\mathrm{CT}$ and nuclear medicine imaging is misguided and detrimental. J Nucl Med 58(6):865-868. https://doi.org/10.2967/jnume d.117.195263

8. Simi S, Ballardin M, Casella M, De Marchi D, Hartwig V, Giovannetti G, Vanello N, Gabbriellini S, Landini L, Lombardi M (2008) Is the genotoxic effect of magnetic resonance negligible? Low persistence of micronucleus frequency in lymphocytes of individuals after cardiac scan. Mutat Res 645(1-2):39-43. https ://doi.org/10.1016/j.mrfmmm.2008.08.011

9. Bonassi S, Norppa H, Ceppi M, Stromberg U, Vermeulen R, Znaor A, Cebulska-Wasilewska A, Fabianova E, Fucic A, Gundy S, Hansteen IL, Knudsen LE, Lazutka J, Rossner P, Sram RJ, Boffetta P (2008) Chromosomal aberration frequency in lymphocytes predicts the risk of cancer: results from a pooled cohort study of 22 358 subjects in 11 countries. Carcinogenesis 29(6):1178-1183. https://doi.org/10.1093/carcin/bgn075

10. Lobrich M, Rief N, Kuhne M, Heckmann M, Fleckenstein J, Rube C, Uder M (2005) In vivo formation and repair of DNA doublestrand breaks after computed tomography examinations. Proc Natl Acad Sci USA 102(25):8984-8989. https://doi.org/10.1073/ pnas.0501895102

11. Kuefner MA, Brand M, Engert C, Schwab SA, Uder M (2015) Radiation induced DNA double-strand breaks in radiology. Rofo 187(10):872-878. https://doi.org/10.1055/s-0035-1553209

12. Leszczynski D, de Pomerai D, Koczan D, Stoll D, Franke H, Albar JP (2012) Five years later: the current status of the use of proteomics and transcriptomics in EMF research. Proteomics 12(15-16):2493-2509. https://doi.org/10.1002/pmic.201200122

13. Imaida K, Hasegawa R, Kato T, Futakuchi M, Takahashi S, Ogawa $\mathrm{K}$, Asamoto M, Yamamoto T, Suzuki K, Inagaki T, Shinagawa N, Shirai T (1997) Clinicopathological analysis on cancers of autopsy cases in a geriatric hospital. Pathol Int 47(5):293-300

14. Magin RL, Lee JK, Klintsova A, Carnes KI, Dunn F (2000) Biological effects of long-duration, high-field (4 T) MRI on growth and development in the mouse. J Magn Reson Imaging 12(1):140-149

15. Arthurs OJ, Edwards A, Austin T, Graves MJ, Lomas DJ (2012) The challenges of neonatal magnetic resonance imaging. Pediatr Radiol 42(10):1183-1194. https://doi.org/10.1007/s0024 7-012-2430-2

16. Salerno S, La Mendola C, Lo Casto A, Mamone G, Caccamo N, Cardinale AE, Salerno S (2006) Reversible effect of MR and ELF magnetic fields ( $0.5 \mathrm{~T}$ and $0.5 \mathrm{mT})$ on human lymphocyte activation patterns. Int J Radiat Biol 82(2):77-85. https://doi. org/10.1080/09553000600589131

17. Salerno S, La Mendola C, La Manna MP, Lo Casto A, Caccamo N, Salerno A (2009) Reversible effect of magnetic fields on human lymphocyte activation patterns: different sensitivity of naive and memory lymphocyte subsets. Radiat Res 172(4):444-450. https ://doi.org/10.1667/RR1761.1

18. Coskun $\mathrm{O}$ (2011) Magnetic resonance imaging and safety aspects. Toxicol Ind Health 27(4):307-313. https://doi.org/10.1177/07482 33710386413

19. Wang Z, Lin JC, Mao W, Liu W, Smith MB, Collins CM (2007) SAR and temperature: simulations and comparison to regulatory limits for MRI. J Magn Reson Imaging 26(2):437-441. https:// doi.org/10.1002/jmri.20977

20. Shellock FG (2000) Radiofrequency energy-induced heating during MR procedures: a review. J Magn Reson Imaging 12(1):30-36

21. Bryan YF, Templeton TW, Nick TG, Szafran M, Tung A (2006) Brain magnetic resonance imaging increases core body temperature in sedated children. Anesth Analg 102(6):1674-1679. https ://doi.org/10.1213/01.ane.0000216292.82271.bc

22. Isaacson DL, Yanosky DJ, Jones RA, Dennehy N, Spandorfer P, Baxter AL (2011) Effect of MRI strength and propofol sedation on pediatric core temperature change. J Magn Reson Imaging 33(4):950-956. https://doi.org/10.1002/jmri.22486

23. Kussman BD, Mulkern RV, Holzman RS (2004) Iatrogenic hyperthermia during cardiac magnetic resonance imaging. Anesth Analg 99(4):1053-1055. https://doi.org/10.1213/01.ANE.00001 33911.79161.AF

24. Machata AM, Willschke H, Kabon B, Prayer D, Marhofer P (2009) Effect of brain magnetic resonance imaging on body 
core temperature in sedated infants and children. $\mathrm{Br} \mathrm{J}$ Anaesth 102(3):385-389. https://doi.org/10.1093/bja/aen388

25. McJury M, Shellock FG (2000) Auditory noise associated with MR procedures: a review. J Magn Reson Imaging 12(1):37-45

26. Laubach V, Wilhelm P, Carter K (2014) Shhh... I'm growing: noise in the NICU. Nurs Clin North Am 49(3):329-344. https ://doi.org/10.1016/j.cnur.2014.05.007

27. MHRA (2007) Device bulletin. Safety guidelines for magnetic resonance imaging equipment in clinical use DB2007(03). Medicines and Healthcare products Regulatory Agency, London

28. Schaefer DJ, Bourland JD, Nyenhuis JA (2000) Review of patient safety in time-varying gradient fields. J Magn Reson Imaging 12(1):20-29

29. Shellock FG (2014) MRI issues for implants and devices. In: Shellock FG, Crues JV (eds) MRI bioeffects, safety, and patient management. Biomedical Research Publishing Group, Playa Del Rey

30. Olsen OE (2008) Imaging of abdominal tumours: CT or MRI? Pediatr Radiol 38(Suppl 3):S452-S458. https://doi.org/10.1007/ s00247-008-0846-5

31. Sury MR, Smith JH (2008) Deep sedation and minimal anesthesia. Paediatr Anaesth 18(1):18-24. https://doi.org/10.111 $1 / j .1460-9592.2007 .02379 . x$

32. Edwards AD, Arthurs OJ (2011) Paediatric MRI under sedation: is it necessary? What is the evidence for the alternatives? Pediatr Radiol 41(11):1353-1364. https://doi.org/10.1007/s0024 7-011-2147-7

33. Masaracchia MM, Tsapakos MJ, McNulty NJ, Beach ML (2017) Changing the paradigm for diagnostic MRI in pediatrics: don't hold your breath. Paediatr Anaesth 27(9):880-884. https://doi. org/10.1111/pan.13165

34. Hall RW, Anand KJ (2014) Pain management in newborns. Clin Perinatol 41(4):895-924. https://doi.org/10.1016/j. clp.2014.08.010

35. Schulte-Uentrop L, Goepfert MS (2010) Anaesthesia or sedation for MRI in children. Curr Opin Anaesthesiol 23(4):513-517. https://doi.org/10.1097/ACO.0b013e32833bb524

36. Gale EM, Caravan P, Rao AG, McDonald RJ, Winfeld M, Fleck RJ, Gee MS (2017) Gadolinium-based contrast agents in pediatric magnetic resonance imaging. Pediatr Radiol 47(5):507-521. https://doi.org/10.1007/s00247-017-3806-0

37. Sherry AD, Caravan P, Lenkinski RE (2009) Primer on gadolinium chemistry. J Magn Reson Imaging 30(6):1240-1248. https://doi.org/10.1002/jmri.21966

38. Grobner T, Prischl FC (2007) Gadolinium and nephrogenic systemic fibrosis. Kidney Int 72(3):260-264. https://doi. org/10.1038/sj.ki.5002338

39. Thomsen HS, Morcos SK, Dawson P (2006) Is there a causal relation between the administration of gadolinium based contrast media and the development of nephrogenic systemic fibrosis (NSF)? Clin Radiol 61(11):905-906. https://doi. org/10.1016/j.crad.2006.09.003

40. Nardone B, Saddleton E, Laumann AE, Edwards BJ, Raisch DW, McKoy JM, Belknap SM, Bull C, Haryani A, Cowper SE, Abu-Alfa AK, Miller FH, Godinez-Puig V, Dharnidharka VR, West DP (2014) Pediatric nephrogenic systemic fibrosis is rarely reported: a RADAR report. Pediatr Radiol 44(2):173-180. https ://doi.org/10.1007/s00247-013-2795-x

41. Kanda T, Ishii K, Kawaguchi H, Kitajima K, Takenaka D (2014) High signal intensity in the dentate nucleus and globus pallidus on unenhanced T1-weighted MR images: relationship with increasing cumulative dose of a gadolinium-based contrast material. Radiology 270(3):834-841. https://doi.org/10.1148/ radiol.13131669

42. Quattrocchi CC, Mallio CA, Errante Y, Beomonte Zobel B (2015) High T1 signal intensity in dentate nucleus after multiple injections of linear gadolinium chelates. Radiology 276(2):616617. https://doi.org/10.1148/radiol.2015150464

43. Errante Y, Cirimele V, Mallio CA, Di Lazzaro V, Zobel BB, Quattrocchi CC (2014) Progressive increase of T1 signal intensity of the dentate nucleus on unenhanced magnetic resonance images is associated with cumulative doses of intravenously administered gadodiamide in patients with normal renal function, suggesting dechelation. Invest Radiol 49(10):685-690. https://doi. org/10.1097/RLI.0000000000000072

44. Tedeschi E, Palma G, Canna A, Cocozza S, Russo C, Borrelli P, Lanzillo R, Angelini V, Postiglione E, Morra VB, Salvatore M, Brunetti A, Quarantelli M (2016) In vivo dentate nucleus MRI relaxometry correlates with previous administration of Gadolinium-based contrast agents. Eur Radiol 26(12):4577-4584. https ://doi.org/10.1007/s00330-016-4245-2

45. Kanda T, Matsuda M, Oba H, Toyoda K, Furui S (2015) Gadolinium deposition after contrast-enhanced MR imaging. Radiology 277(3):924-925. https://doi.org/10.1148/radiol.2015150697

46. Radbruch A, Weberling LD, Kieslich PJ, Hepp J, Kickingereder P, Wick W, Schlemmer HP, Bendszus M (2015) High-signal intensity in the dentate nucleus and globus pallidus on unenhanced T1-weighted images: evaluation of the macrocyclic gadoliniumbased contrast agent gadobutrol. Invest Radiol 50(12):805-810. https://doi.org/10.1097/RLI.0000000000000227

47. Stojanov D, Aracki-Trenkic A, Benedeto-Stojanov D (2016) Gadolinium deposition within the dentate nucleus and globus pallidus after repeated administrations of gadolinium-based contrast agents-current status. Neuroradiology 58(5):433-441. https://doi. org/10.1007/s00234-016-1658-1

48. Hu HH, Pokorney A, Towbin RB, Miller JH (2016) Increased signal intensities in the dentate nucleus and globus pallidus on unenhanced T1-weighted images: evidence in children undergoing multiple gadolinium MRI exams. Pediatr Radiol 46(11):15901598. https://doi.org/10.1007/s00247-016-3646-3

49. Flood TF, Stence NV, Maloney JA, Mirsky DM (2017) Pediatric brain: repeated exposure to linear gadolinium-based contrast material is associated with increased signal intensity at unenhanced T1-weighted MR imaging. Radiology 282(1):222-228. https://doi.org/10.1148/radiol.2016160356

50. Radbruch A, Haase R, Kickingereder P, Baumer P, Bickelhaupt S, Paech D, Wick W, Schlemmer HP, Seitz A, Bendszus M (2017) Pediatric brain: no increased signal intensity in the dentate nucleus on unenhanced T1-weighted MR images after consecutive exposure to a macrocyclic gadolinium-based contrast agent. Radiology 283(3):828-836. https://doi.org/10.1148/radiol.20171 62980

51. Roberts DR, Chatterjee AR, Yazdani M, Marebwa B, Brown T, Collins H, Bolles G, Jenrette JM, Nietert PJ, Zhu X (2016) Pediatric patients demonstrate progressive T1-weighted hyperintensity in the dentate nucleus following multiple doses of gadoliniumbased contrast agent. AJNR Am J Neuroradiol 37(12):2340-2347. https://doi.org/10.3174/ajnr.A4891

52. Maximova N, Gregori M, Zennaro F, Sonzogni A, Simeone R, Zanon D (2016) Hepatic gadolinium deposition and reversibility after contrast agent-enhanced MR imaging of pediatric hematopoietic stem cell transplant recipients. Radiology 281(2):418426. https://doi.org/10.1148/radiol.2016152846

53. Rossi Espagnet MC, Bernardi B, Pasquini L, Figa-Talamanca L, Toma P, Napolitano A (2017) Signal intensity at unenhanced T1-weighted magnetic resonance in the globus pallidus and dentate nucleus after serial administrations of a macrocyclic gadolinium-based contrast agent in children. Pediatr Radiol. https://doi. org/10.1007/s00247-017-3874-1

54. McDonald JS, McDonald RJ, Jentoft ME, Paolini MA, Murray DL, Kallmes DF, Eckel LJ (2017) Intracranial gadolinium deposition following gadodiamide-enhanced magnetic resonance 
imaging in pediatric patients: a case-control study. JAMA Pediatr 171(7):705-707. https://doi.org/10.1001/jamapediat rics.2017.0264

55. Murata N, Murata K, Gonzalez-Cuyar LF, Maravilla KR (2016) Gadolinium tissue deposition in brain and bone. Magn Reson Imaging 34(10):1359-1365. https://doi.org/10.1016/j. mri.2016.08.025

56. McDonald RJ, McDonald JS, Kallmes DF, Jentoft ME, Murray DL, Thielen KR, Williamson EE, Eckel LJ (2015) Intracranial gadolinium deposition after contrast-enhanced MR imaging. Radiology 275(3):772-782. https://doi.org/10.1148/radiol.15150025

57. Roberts DR, Welsh CA, LeBel DP 2nd, Davis WC (2017) Distribution map of gadolinium deposition within the cerebellum following GBCA administration. Neurology 88(12):1206-1208. https://doi.org/10.1212/WNL.0000000000003735

58. Frenzel T, Apte C, Jost G, Schockel L, Lohrke J, Pietsch H (2017) Quantification and assessment of the chemical form of residual gadolinium in the brain after repeated administration of gadolinium-based contrast agents: comparative study in rats. Invest Radiol 52(7):396-404. https://doi.org/10.1097/RLI.0000000000 000352

59. Lohrke J, Frisk AL, Frenzel T, Schockel L, Rosenbruch M, Jost G, Lenhard DC, Sieber MA, Nischwitz V, Kuppers A, Pietsch $\mathrm{H}$ (2017) Histology and gadolinium distribution in the rodent brain after the administration of cumulative high doses of linear and macrocyclic gadolinium-based contrast agents. Invest Radiol 52(6):324-333. https://doi.org/10.1097/RLI.0000000000000344

60. Robert P, Violas X, Grand S, Lehericy S, Idee JM, Ballet S, Corot C (2016) Linear gadolinium-based contrast agents are associated with brain gadolinium retention in healthy rats. Invest Radiol 51(2):73-82. https://doi.org/10.1097/RLI.0000000000000241

61. European Medicines Agency (2017) EMA's final opinion confirms restrictions on use of linear gadolinium agents in body scans. European Medicines Agency, London

62. Thomsen HS, Morcos SK, Almen T, Bellin MF, Bertolotto M, Bongartz G, Clement O, Leander P, Heinz-Peer G, Reimer P, Stacul F, van der Molen A, Webb JA, Committee ECMS (2013) Nephrogenic systemic fibrosis and gadolinium-based contrast media: updated ESUR Contrast Medium Safety Committee guidelines. Eur Radiol 23(2):307-318. https://doi.org/10.1007/s0033 0-012-2597-9
63. Bedoya MA, White AM, Edgar JC, Pradhan M, Raab EL, Meyer JS (2017) Effect of intravenous administration of contrast media on serum creatinine levels in neonates. Radiology 284(2):530 540. https://doi.org/10.1148/radiol.2017160895

64. Dillman JR, Ellis JH, Cohan RH, Strouse PJ, Jan SC (2007) Frequency and severity of acute allergic-like reactions to gadolinium-containing i.v. Contrast media in children and adults. AJR Am J Roentgenol 189(6):1533-1538. https://doi.org/10.2214/ AJR.07.2554

65. Dillman JR, Strouse PJ, Ellis JH, Cohan RH, Jan SC (2007) Incidence and severity of acute allergic-like reactions to i.v. Nonionic iodinated contrast material in children. AJR Am J Roentgenol 188(6):1643-1647. https://doi.org/10.2214/AJR.06.1328

66. Jung JW, Kang HR, Kim MH, Lee W, Min KU, Han MH, Cho SH (2012) Immediate hypersensitivity reaction to gadoliniumbased MR contrast media. Radiology 264(2):414-422. https://doi. org/10.1148/radiol.12112025

67. Watson TA, Olsen OE (2015) Fusion and subtraction post-processing in body MRI. Pediatr Radiol 45(2):273-282. https://doi. org/10.1007/s00247-014-3129-3

68. Villani A, Greer MC, Kalish JM, Nakagawara A, Nathanson KL, Pajtler KW, Pfister SM, Walsh MF, Wasserman JD, Zelley K, Kratz CP (2017) Recommendations for cancer Surveillance in individuals with RASopathies and other rare genetic conditions with increased cancer risk. Clin Cancer Res 23(12):e83-e90. https ://doi.org/10.1158/1078-0432.CCR-17-0631

69. Greer MC, Voss SD, States LJ (2017) Pediatric cancer predisposition imaging: focus on whole-body MRI. Clin Cancer Res 23(11):e6-e13. https://doi.org/10.1158/1078-0432.CCR-17-0515

70. Ray JG, Vermeulen MJ, Bharatha A, Montanera WJ, Park AL (2016) Association between MRI exposure during pregnancy and fetal and childhood outcomes. JAMA 316(9):952-961

71. http://www.who.int/peh-emf/publications/facts/fs299/en/. Accessed Feb 2018

72. Nievelstein RA, Littooij AS (2016) Whole-body MRI in paediatric oncology. Radiol Med 121(5):442-453. https://doi.org/10.1007/ s11547-015-0600-7

73. Ording Muller LS, Avenarius D, Olsen OE (2011) High signal in bone marrow at diffusion-weighted imaging with body background suppression (DWIBS) in healthy children. Pediatr Radiol 41(2):221-226. https://doi.org/10.1007/s00247-010-1774-8 